\title{
NIR is a novel INHAT repressor that modulates the transcriptional activity of p53
}

\author{
Philip Hublitz, ${ }^{1,6}$ Natalia Kunowska, ${ }^{1,6}$ Ulrich P. Mayer, ${ }^{1}$ Judith M. Müller, ${ }^{1}$ Kristina Heyne, ${ }^{2}$ \\ Na Yin, ${ }^{1}$ Claudia Fritzsche, ${ }^{2}$ Cecilia Poli, ${ }^{1}$ Laurent Miguet,${ }^{3}$ Ingo W. Schupp, ${ }^{4}$ \\ Leo A. van Grunsven, ${ }^{5}$ Noëlle Potiers, ${ }^{3}$ Alain van Dorsselaer, ${ }^{3}$ Eric Metzger, ${ }^{1}$ Klaus Roemer, ${ }^{2}$ \\ and Roland Schüle ${ }^{1,7}$

\begin{abstract}
${ }^{1}$ Frauenklinik der Albert-Ludwigs-Universität Freiburg, Zentrale Klinische Forschung, D-79106 Freiburg, Germany; ${ }^{2}$ University of Saarland Medical School, Institute of Virology, D-66421 Homburg, Germany; ${ }^{3}$ Laboratoire de Spectrométrie de Masse Bio-Organique, Ecole de Chimie, Polymères et Matériaux, F-67089 Strasbourg, France; ${ }^{4}$ Deutsches Krebsforschungszentrum DKFZ, Abteilung Molekulare Genomanalyse, Im Neuenheimer Feld 280, D-69120 Heidelberg, Germany; ${ }^{5}$ Department of Developmental Biology, VIB and Laboratory of Molecular Biology (Celgen), University of Leuven, B-3000 Leuven, Belgium
\end{abstract}

\begin{abstract}
Most transcriptional repression pathways depend on the targeted deacetylation of histone tails. In this report, we characterize NIR, a novel transcriptional corepressor with inhibitor of histone acetyltransferase (INHAT) activity. NIR (Novel INHAT Repressor) is ubiquitously expressed throughout embryonic development and adulthood. NIR is a potent transcriptional corepressor that is not blocked by histone deacetylase inhibitors and is capable of silencing both basal and activator-driven transcription. NIR directly binds to nucleosomes and core histones and prevents acetylation by histone acetyltransferases, thus acting as a bona fide INHAT. Using a tandem affinity purification approach, we identified the tumor suppressor p53 as a NIR-interacting partner. Association of p53 and NIR was verified in vitro and in vivo. Upon recruitment by p53, NIR represses transcription of both p53-dependent reporters and endogenous target genes. Knock-down of NIR by RNA interference significantly enhances histone acetylation at p53-regulated promoters. Moreover, p53-dependent apoptosis is robustly increased upon depletion of NIR. In summary, our findings describe NIR as a novel INHAT that plays an important role in the control of p53 function.
\end{abstract}

[Keywords: INHAT; transcription; HDAC-independent repression; p53]

Supplemental material is available at http://www.genesdev.org.

Received May 11, 2005; revised version accepted September 22, 2005.

There is growing evidence that major aspects of transcriptional regulation can be explained by the histone code model (Strahl and Allis 2000). The covalent modification of the $\mathrm{N}$ termini of core histones by transfer and removal of acetyl, methyl, or phospho groups determines whether a candidate gene is expressed or remains in a silenced state. A major mechanistic principle in transcriptional activation has been unraveled by the discovery of basal and recruited transcriptional coactivators that contain histone acetyltransferase (HAT) activity (Mizzen et al. 1996; Ogryzko et al. 1996). Transfer of acetyl groups to lysine residues in histone tails weakens the tight contact between DNA and nucleosomes, and

\footnotetext{
${ }^{6}$ These authors contributed equally to this work.

${ }^{7}$ Corresponding author.

E-MAIL roland.schuele@uniklinik-freiburg.de; FAX 49-761-270-6311. Article and publication are at http://www.genesdev.org/cgi/doi/10.1101/ gad.351205.
}

decompacted chromatin is thus rendered accessible to the action of the RNA-polymerase II holoenzyme complex (Glass and Rosenfeld 2000). Consequently, the return to silenced chromatin or the specific repression of target genes requires enzymatic activities that counteract the action of coactivators. Therefore, a commonly used mechanism for short-term repression involves the enzymatic action of histone deacetylating enzymes (HDACs). Most repressors have been reported to recruit diverse HDAC-containing complexes (Jepsen and Rosenfeld 2002). HDACs are grouped into three classes based on their similarity to known yeast factors, structural features, and their subcellular localization (Verdin et al. 2003). Class I and class II HDACs are sensitive to inhibitors such as Trichostatin A (TSA) or Na-butyrate, whereas class III HDACs are blocked by nicotinamide. In contrast to the wealth of information on HDAC-dependent repression pathways, there are only a few studies that describe HDAC-independent repression (Deltour et 
al. 1999; Sun and Taneja 2000; Koipally and Georgopoulos 2002; Christian et al. 2004).

A multiprotein complex has been described that inhibits the HAT activity of the major histone acetyltransferases p300/CBP and p/CAF on histone substrates (Seo et al. 2001). The active moiety of this complex, the Set/ TAF1 $\beta$ oncoprotein, binds to histone tails and blocks the access of HATs to their histone substrates. This complex and its novel activity were referred to as INHAT, inhibitor of histone acetyltransferases. Subsequently, another protein of the Set INHAT complex named pp32 (Seo et al. 2002), the polyglutamine-tract-containing protein Ataxin-3 (Li et al. 2002), and the corepressor PELP1 (Choi et al. 2004) were shown to contain INHAT activity. Set/ TAF1 $\beta$ and pp32 preferably bind to hypoacetylated histones, while acetylation of histones H3 and H4 abrogates binding of INHAT subunits (Kutney et al. 2004; Schneider et al. 2004). The INHAT subunits Set/TAF1 $\beta$ and pp32 associate with HDAC activity, suggesting a more global function of the previously characterized INHATs by linking targeted deacetylation and maintenance of the unmodified status (Kutney et al. 2004).

p53 is a tumor suppressor that is activated in response to various stress signals. p53 function is mediated largely through the action as a DNA-binding transcription factor that recruits transcriptional cofactors to regulate genes that control cell cycle, cell growth, or apoptosis (Vogelstein et al. 2000). Recent studies demonstrated p53-dependent recruitment of p300 and targeted acetylation of histones at p53-responsive genes (Espinosa and Emerson 2001; Liu et al. 2003; Espinosa et al. 2003). Nevertheless, to date little is known about transcriptional corepressors that counteract p53-mediated transcriptional activation (Allison and Milner 2004).

In this work we characterize the novel corepressor NIR (Novel INHAT Repressor). NIR binds to nucleosomes and histones and blocks their acetylation by histone acetyltransferases, thus acting as a bona fide INHAT. We identify the tumor suppressor p53 as a NIR-interacting partner and demonstrate that, upon recruitment, NIR inhibits p53-activated gene expression and regulates p53-mediated apoptosis. Thus, NIR is the first INHAT repressor that plays an important role in the control of p53 function.

\section{Results}

\section{Cloning of NIR}

In order to define new pathways in transcriptional regulation, we searched for novel INHAT repressors. We applied low-stringency iterative BLAST analyses to screen databases for proteins with putative INHAT regions. By this in silico approach, we identified a cDNA coding for an unknown protein that we named NIR. The human full-length NIR cDNA was obtained from a prostate cDNA library by PCR. Sequence analysis confirmed that the NIR cDNA corresponds to the deposited sequence with the accession number BC003555. The human NIR locus codes for a 749-amino-acid protein (Fig. 1) with orthologs present from worms to mammals (Supplemen-

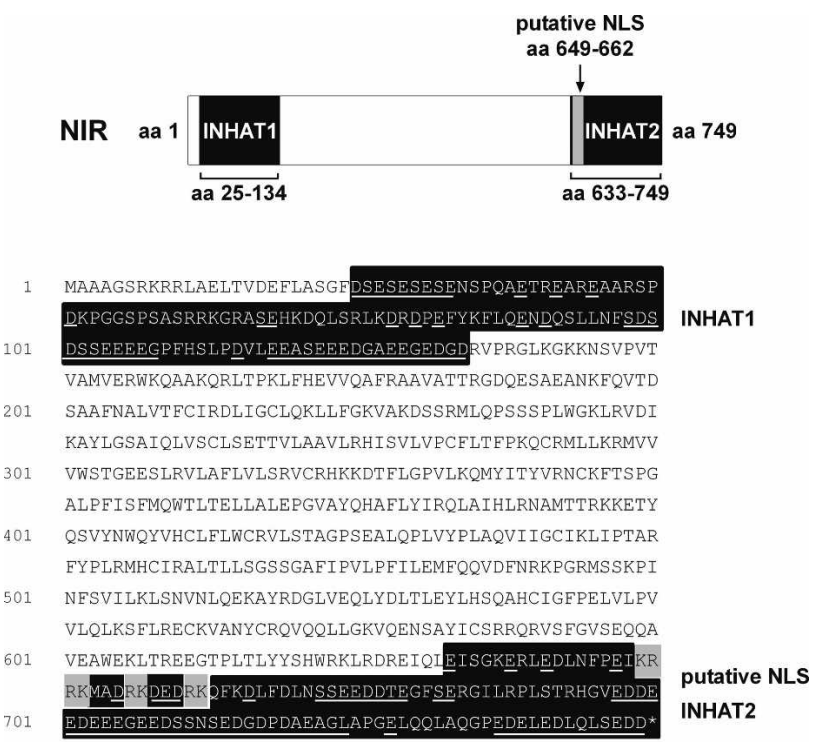

Figure 1. Schematic representation and sequence of human NIR. (Top) Schematic representation of the human NIR protein. (Bottom) Amino acid sequence and functional motifs in NIR. INHAT regions are shaded in black. Set/TAF1 $\beta$ homology regions are underlined white. The putative bipartite nuclear localization signal (NLS) is in gray.

tary Fig. 1). The cDNA of the murine ortholog was also cloned, and sequence analyses verified the deposited partial sequence (accession no. AF155546) (Supplementary Fig. 2). Bioinformatic analyses suggested that NIR harbors two INHAT regions, one at its $\mathrm{N}$ terminus and one at its $\mathrm{C}$ terminus. A homology alignment of NIR with the INHAT domains of published human INHAT proteins is displayed in Supplementary Figure 3. Additionally, NIR contains a putative bipartite nuclear localization signal (NLS).

\section{NIR is ubiquitously expressed}

As shown by RT-PCR analyses, Nir mRNA was present at all analyzed stages of mouse embryogenesis (Fig. 2A). Consistent with the mRNA expression profile, Nir protein was detected at all murine embryonic stages analyzed. A representative immunohistochemical analysis at embryonic day 9.5 (E9.5) shows ubiquitous Nir protein expression (Fig. 2B). RT-PCR analyses detected mouse Nir mRNA to varying extents in all adult tissues examined (Fig. 2C), and in accordance with this finding, mRNA dot blot assays showed expression of human NIR mRNA in all tissues tested (Fig. 2D). Northern blot analyses revealed the presence of a single NIR transcript of $3.3 \mathrm{~kb}$ (Supplementary Fig. 4). In summary, NIR is ubiquitously expressed during embryonic development and in adult tissues.

\section{NIR is an inhibitor of histone acetylation}

Since NIR contains two putative INHAT regions, we assayed for a direct interaction of NIR with core histones and nucleosomes. In GST-pulldown experiments, we 
Hublitz et al.

A

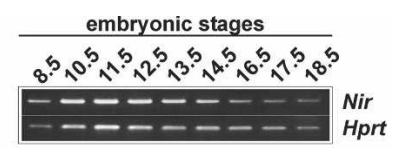

B

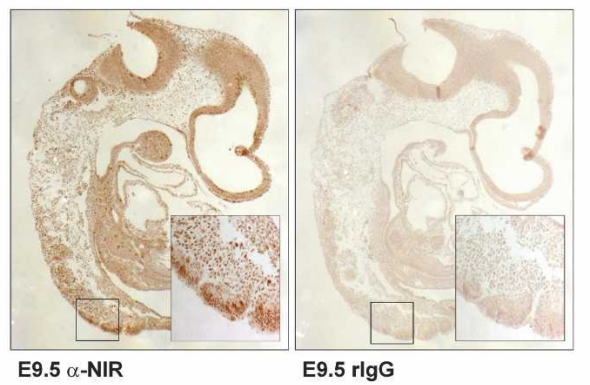

C

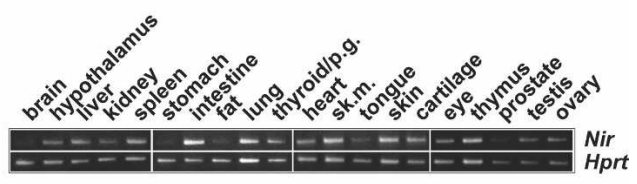

D

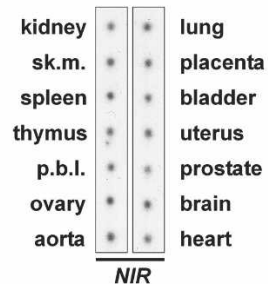

Figure 2. NIR expression analyses. (A) Expression of Nir during mouse embryogenesis. RT-PCR analyses were performed at the indicated stages from E8.5 to E18.5. (B, left) Expression of Nir in sagittal sections of E9.5 mice. Nir is expressed throughout the embryo. Higher magnification exemplifies Nir expression in the somites. The right panel displays staining with a control antibody. (C) Nir expression in tissues of adult mice as determined by RT-PCR. (D) Expression of NIR in human adult tissues. mRNA dot-blot hybridization shows that NIR is ubiquitously expressed in human adult tissues. (p.b.l.) Peripheral blood lymphocytes, (sk.m.) skeletal muscle, (thyroid/p.g.) thyroid and parathyroid gland.

demonstrated physical interaction of both the GSTtagged $\mathrm{N}$ and $\mathrm{C}$ termini (INHAT1 and INHAT2, respectively) with calf thymus core histones and nucleosomes isolated from HeLa cells (Fig. 3A). The unrelated control protein GST-Nixl (Greiner et al. 2000) did not interact, thus demonstrating specific interaction of both INHAT regions. Sepharose-pulldown assays showed direct interaction between NIR and the unmodified N-terminal tail of histone $\mathrm{H} 3$ comprising amino acids 1-30 (Fig. 3B). Similarly to the previously described INHAT subunits (Kutney et al. 2004; Schneider et al. 2004), acetylation of the histone $\mathrm{H} 3$ tail (combinations of acetylated K9, K14, K18, and K23) blocked the association with NIR.

Subsequently, we tested the ability of NIR to directly block acetylation of core histones. Both putative NIR INHAT regions were expressed as His-tagged proteins and then individually preincubated with each of the four core histones. After addition of enzymatically active p300 HAT-domain and $\left[{ }^{14} \mathrm{C}\right]$-labeled acetyl-CoA substrate, histone acetylation was analyzed by autoradiography (Fig. 3C, left panel). Addition of either of the putative NIR INHAT regions robustly reduced acetylation of all core histones by the histone acetyltransferase p300. The unrelated control protein Nixl did not alter acetylation by $\mathrm{p} 300$, thus corroborating specific action of both INHAT domains. Coomassie staining revealed equal amounts of His-tagged proteins and excluded degradation of the core histones (Fig. 3C, right panel). In the same assay system, both NIR INHAT domains also blocked acetylation of core histones $\mathrm{H} 3$ and $\mathrm{H} 4$ by p/CAF (Supplementary Fig. 5).

Since neither full-length NIR nor NIR $\triangle$ INHAT1/2, which lacks both INHAT domains, could be recombinantly expressed in Escherichia coli, we affinity-purified full-length TAP-tagged NIR (NIR-TAP), NIR INHAT1TAP, NIR INHAT2-TAP, and NIR $\triangle$ INHAT1/2-TAP from 293 cells. NIR-TAP as well as NIR INHAT1-TAP and NIR INHAT2-TAP associated efficiently with nucleosomes, whereas the central part of NIR (NIR $\triangle \mathrm{INHAT1} / 2$-TAP) failed to do so (Fig. 3D, middle panel). Consequently, TAP-tagged NIR, NIR INHAT1, and NIR INHAT2 significantly blocked acetylation of core histones and nucleosomes by p300 in INHAT assays (Fig. $3 \mathrm{D}$, bottom panel). In contrast, NIR $\triangle$ INHAT1/2-TAP did not inhibit acetylation, thus serving as an internal control. Ponceau S staining revealed equal amounts of nucleosomes in all reactions, excluding degradation of the substrate by the purified NIR proteins (Fig. 3D, bottom panel). In summary, these data demonstrate that NIR contains two independent INHAT domains and establish NIR as a novel functional INHAT.

\section{NIR is an HDAC-independent transcriptional repressor}

To analyze the effects of NIR on transcription, a Gal4 DNA-binding domain NIR fusion protein was tested in transient transfections. Gal-NIR potently repressed both minimal and complex Gal-dependent promoters in a dose-dependent manner in all cell lines tested (Fig. 4A). To verify whether NIR is able to repress activator-driven transcription, we performed experiments with a combined LexA/Gal-reporter (Lemercier et al. 2000). LexAVP16-mediated activation was severely inhibited by cotransfection of Gal-NIR, whereas LexA-VP16 activation was not significantly impeded by cotransfection of the unrelated cofactor Gal-Nix1 (Fig. 4B, upper panel). The potent repressive effect of NIR was also observed in the reverse set-up in which LexA-NIR suppressed activation by the transcriptional activator Gal-CREB as well as the transcriptional coactivator Gal-TIF2 (Fig. 4B, lower panels). In summary, these data demonstrate that promoterrecruited NIR is able to repress basal as well as activated transcription in a cell-line- and promoter-independent manner.

Next, we addressed a potential effect of HDACs in NIR-mediated repression. Addition of the class I and class II HDAC inhibitors TSA or Na-butyrate, or the inhibitor of $\mathrm{NAD}^{+}$-dependent class III deacetylases, nico- 
A

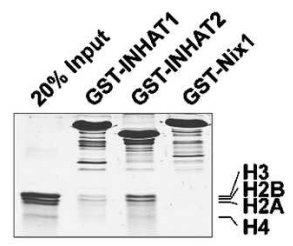

Core histone preparation

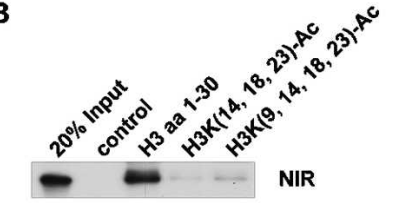

NH3-ARTKQTARKSTGGKAPRKQLATKAARKSAP - sepharose

C

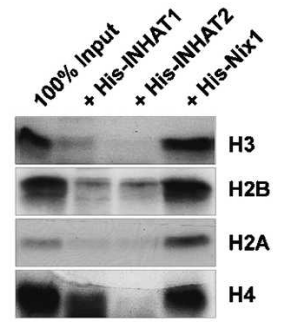

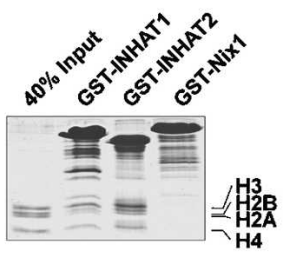

Nucleosomal preparation

\section{西}

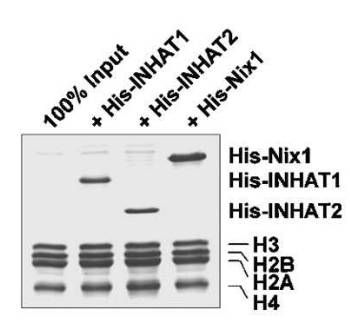

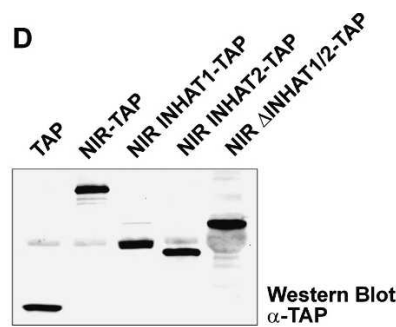
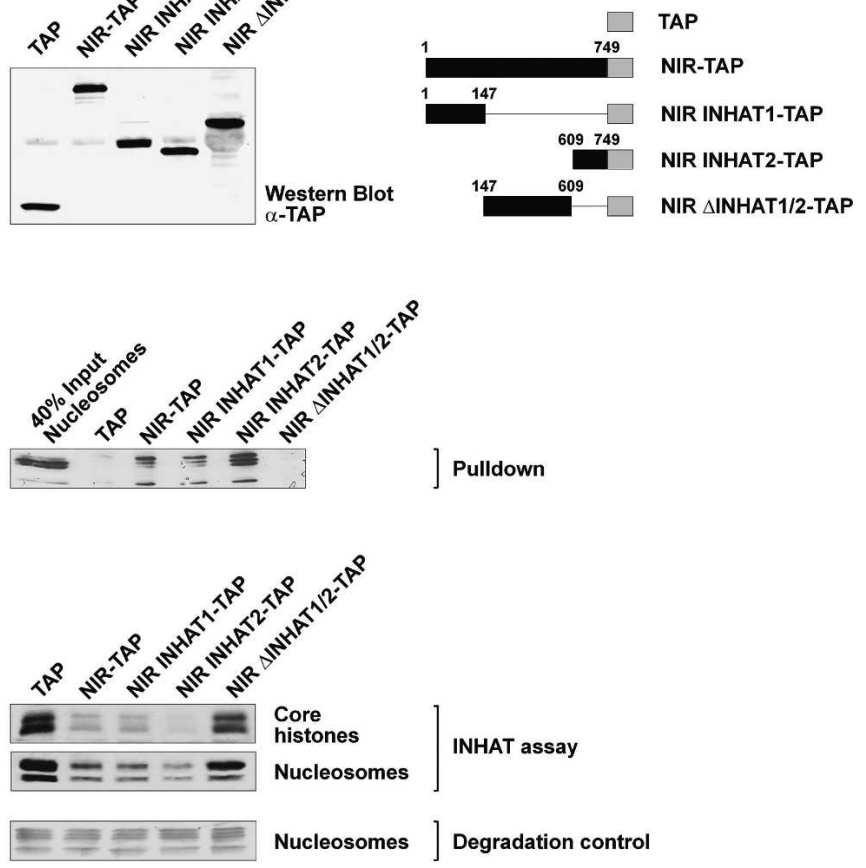

Figure 3. NIR is an inhibitor of histone acetylation. (A) NIR interacts with core histones and nucleosomes in vitro. Bacterially expressed GST-NIR INHAT domains interact with core histones (left panel) and nucleosomes (right panel). The unrelated protein Nix1 serves as a control. Proteins are visualized by Coomassie staining. $(B)\left[{ }^{35} S\right]$ methionine-labeled in vitro translated NIR interacts with nonacetylated Sepharose-coupled peptides corresponding to the N-terminal tail of histone H3 (amino acids 1-30). Acetylation at K9, $\mathrm{K} 14$, K18, or K23 no longer permits binding of NIR. Interaction of radioactively labeled NIR with histone tails is visualized by autoradiography. $(C)$ NIR is a functional INHAT. (Left panel) Bacterially expressed NIR INHAT regions prevent acetylation of all core histones by the p300 histone acetyltransferase in vitro. To demonstrate specificity, the unrelated protein Nix1 is used as a control. INHAT activity is visualized by autoradiography. (Right panel) The Coomassie stain verifies the use of equal amounts of His-tagged proteins and absence of protease contaminations that could potentially degrade histones. $(D)$ Full-length NIR-TAP and the indicated deletion mutants were tested for association with nucleosomes and INHAT activity. (Upper panel) Equal amounts of TAP fusion proteins are visualized by Western blotting. (Middle panel) Pulldown of NIR-TAP proteins with nucleosomes. The lower panel displays the INHAT assays using either core histones or nucleosomes as substrates and full-length NIR-TAP or the indicated mutants. Full-length NIR and both INHAT-domains block acetylation by the p300. INHAT activity is visualized by autoradiography. Ponceau $S$ staining verifies the presence of equal amounts of nucleosomes and excludes protease contamination of affinity-purified NIR proteins.

tinamide, did not block NIR-mediated repression (Fig. 4C). The increase in fold repression by Gal-NIR upon addition of TSA or Na-butyrate results from the fact that both inhibitors significantly increase basal transcription levels of Gal-DBD (that harbors a weak minimal transactivation function), whereas repression by Gal-NIR was not influenced. The functionality of the HDAC inhibitors in our assay system was verified (Supplementary Fig. 6). Importantly, immunopurified NIR did not display detectable activity in HDAC assays (Fig. 4D). Moreover, NIR does not associate with HDACs or diverse members of different corepressor families (Supplementary Fig. 7). These results reveal that the novel INHAT NIR, in contrast to PELP1 and Set/TAF1 $\beta$, functions independently of HDAC activity.

\section{$N I R$ is a novel interaction partner of p53}

To understand the biological function of NIR, we isolated NIR-associated proteins by tandem affinity purifi- cation from 293 cells. NIR-associated proteins were analyzed by MALDI-TOF/TOF. Among other proteins, we identified the tumor suppressor p53 as a NIR-interacting transcription factor (Supplementary Fig. 9). To visualize the cellular localization of both proteins, we performed immunofluorescence analyses in cells that were treated with the DNA-damaging agent doxorubicin to increase endogenous p53 protein levels. It is important to note that under these conditions NIR protein levels were not detectably altered (Supplementary Fig. 10). Confocal laser scanning microscopy revealed colocalization of endogenous p53 and NIR in the nucleus (Fig. 5A). NIR and p53 directly interacted in GST-pulldown assays in vitro (Fig. 5B). The p53-interaction domain localizes to the central part of NIR, spanning amino acids 147-609. The NIR-interaction domain in p53 comprises the DNAbinding domain (amino acids 102-292) and the C-terminal tetramerization domain (amino acids 293-359). To demonstrate association between p53 and NIR in vivo, 
Hublitz et al.

A
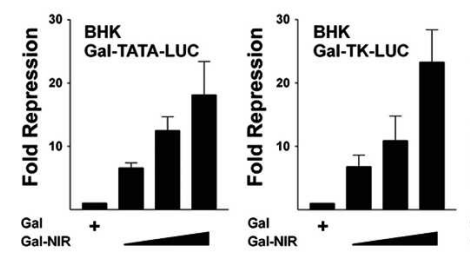

$\underset{\text { Gal.NIR }}{\text { Gal }}+$
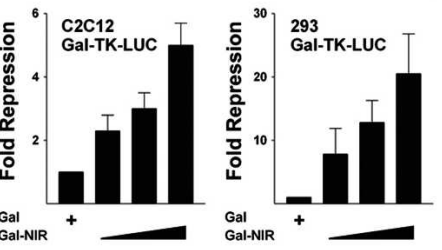

B

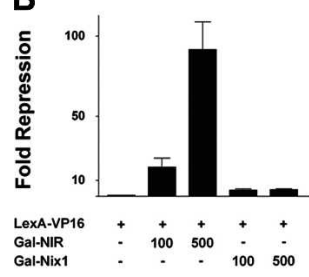

L8G5-LUC

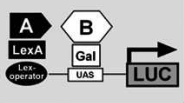

BHK
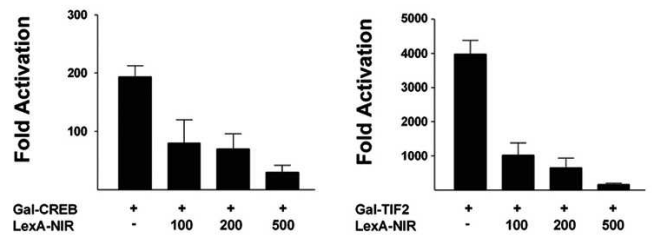

Figure 4. NIR is a potent HDAC-independent transcriptional repressor. (A) Gal-NIR represses transcription of synthetic minimal or complex Gal-dependent reporters in a dose-dependent manner in various cell lines. In transient transfection assays, 50, 100, or 500 ng of Gal-NIR expression plasmid were used. As a control, the corresponding amounts of Gal4-DBD (Gal) were transfected. (B) NIR represses activated transcription. BHK cells were cotransfected with $500 \mathrm{ng}$ of L8G5-LUC reporter and 100 ng of LexA-VP16, GalCREB, or Gal-TIF2 expression plasmids. Fold activation is calculated in relation to the corresponding amounts of Gal4-DBD. (C) NIR repression is not influenced by HDAC inhibitors. BHK cells were cotransfected with $500 \mathrm{ng}$ of Gal-TK-LUC reporter and 50 ng of Gal-NIR expression plasmid. Na-butyrate $(5 \mathrm{mM})$, nicotinamide $(10 \mathrm{mM})$, and TSA $(330 \mathrm{nM})$ were applied for $24 \mathrm{~h}$ post-transfection. Fold repression is calculated in relation to the corresponding amounts of Gal4-DBD. $(D)$ NIR is not associated with HDAC activity. NIR and associated complexes were immunopurified from 293 cells with an $\alpha$-NIR (2719) antibody. Release of radiolabeled acetyl groups from $\mathrm{H} 3$ peptides is observed only when using whole-cell extract (w.c.e.) or purified N-CoR-associated complexes. The amount of released radiolabeled acetyl groups (measured by $\beta$-counting) in NIR immunoprecipitates corresponds to the mock-treated reactions or to the release control. Specificity of the reactions is demonstrated by using the HDAC-inhibitor TSA. Bars represent mean \pm SD $(n \geq 6)$.

extracts from BHK cells transfected with expression plasmids for myc-p53 and NIR-TAP were immunoprecipitated using an $\alpha$-TAP antibody. Western blot analyses showed that p53 is specifically coprecipitated in the presence of NIR-TAP (Fig. 5C). Identical results were obtained using another cell line and performing the immunoprecipitations with $\alpha$-p53 and $\alpha$-myc antibodies (Supplementary Fig. 11). Importantly, we verified association of p53 and NIR endogenously expressed in 293 cells or wild-type p53-containing HCT116/p53 $3^{+/+}$cells (untreated or treated with doxorubicin for 6 h) (Fig. 5D), thus demonstrating interaction in vivo. In summary, the data identify NIR as the first p53-interacting INHAT.

\section{NIR modulates p53 function}

To address the relevance of the interaction between p53 and NIR, we analyzed the consequence of NIR expression on p53 target genes. In transient transfection experiments performed in the p53-negative cell lines Saos-2 and HCT116/p53/-, NIR suppressed, in a dose-depen- dent manner, the activation of the synthetic minimal PG13-reporter mediated by exogenous p53 (Fig. 6A). The control reporter MG15 that contains mutated p53-binding sites was unaffected by transfection of either p53 or NIR, thus demonstrating specificity. Moreover, p53-mediated activation of the p21, PIG3, and Noxa promoters was inhibited by cotransfection of NIR. The equivalent promoters containing mutated p53-binding sites did not respond significantly to p53 or NIR (Supplementary Fig. 12). In addition, NIR failed to block activity of other transcription factors such as CBF1, androgen receptor (AR), or thyroid hormone receptor (TR), further confirming specificity (Supplementary Fig. 13). RT-PCR analyses showed that exogenous NIR significantly down-regulated doxorubicin-induced expression of endogenous p53 target genes such as NOXA, p21, and PIG3 in HCT116/ p53 $3^{+/+}$cells (Fig. 6B). In contrast, transfection of NIR in HCT116/p53-/- cells yielded no detectable change in p53 target gene expression.

To determine whether p53 recruits NIR to chromatin in vivo, HCT116/p53-/- cells, which express NIR endog- 
A

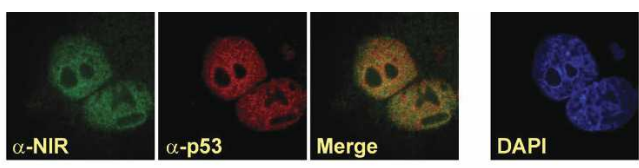

B
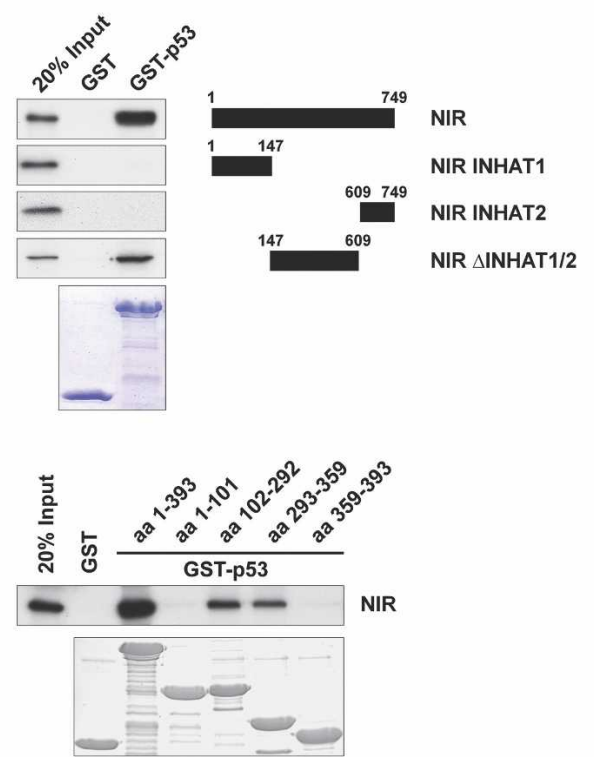

C

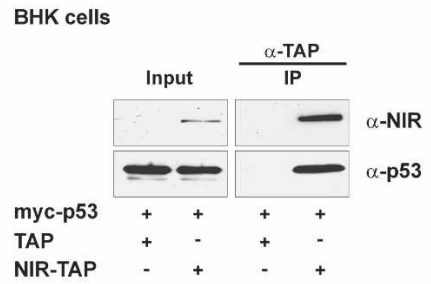

D

293 cells

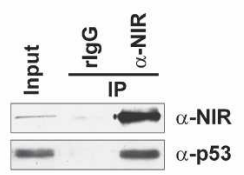

HCT116/p53+/+ cells

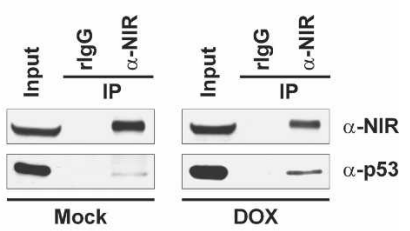

Figure 5. NIR interacts with p53 in vitro and in vivo. (A) NIR is a nuclear protein and colocalizes with p53 in vivo in BHK cells. NIR immunoreactivity is displayed in green, p53 in red. Nuclei were stained with DAPI (blue). For clarity, the merge image displays only NIR and p53 immunoreactivity. (B) p53 and NIR interact in vitro. Interaction domains were mapped in GST-pulldown assays using GST-p53, GST-p53 deletion mutants, and $\left[{ }^{35} \mathrm{~S}\right]$ methionine-labeled in vitro translated NIR or mutants thereof. The use of equal amounts of GST fusion proteins is demonstrated by Coomassie staining. (C) Coimmunoprecipitation of TAP-tagged NIR and myctagged p53 in BHK cells. Membranes were decorated with the $\alpha$-NIR 2910 or the $\alpha$-p53 DO-1 antibody. Five percent of whole-cell extract was used as input. $(D)$ Endogenous p53 coimmunoprecipitates with NIR. Whole-cell extracts from 293 cells and nuclear extracts from HCT116/p53 $3^{+/+}$cells mock-treated or treated with doxorubicin (DOX) were immunoprecipitated with the $\alpha$-NIR 2910 antibody. Membranes were decorated with $\alpha$-NIR (2910) or $\alpha$-p53 (DO-1) antibody. We used $2.5 \%$ and $25 \%$ of whole-cell extract as inputs for p53 and NIR, respectively.

enously, were transfected with a p53 expression construct and subjected to chromatin immunoprecipitation (ChIP). Genomic DNA corresponding to the p53 response elements located in the promoters of the $p 21$ and PIG3 genes was immunoprecipitated with either $\alpha$-NIR or $\alpha$-p53 antibodies only in the cells that expressed exogenous p53 (Fig. 6C). Association of NIR and p53 with the $p 21$ and PIG3 promoters is specific, since genomic DNA from the promoters of the U6 and GAPDH genes was not enriched. Next, we verified that NIR and p53 endogenously expressed in HCT116/p53 $3^{+/+}$cells specifically associate with the p21 promoter (Fig. 6D, left panel). In contrast, NIR failed to do so in HCT116/p53 ${ }^{-/-}$ cells (Fig. 6D, right panel), further demonstrating that NIR associates with the $p 21$ promoter in a p53-dependent manner. Indeed, a sequential ChIP (Re-ChIP), first with an $\alpha$-NIR antibody followed by either $\alpha$-p 53 antibody or control mouse IgG, demonstrated that NIR and p53 form a complex on chromatin (Fig. 6E, upper panel). Cellular stress, induced by treatment with doxorubicin, increased the occupancy of the $p 21$ promoter by p53, but did not alter its occupancy by NIR (Fig. 6E, bottom panel).

To study the effects of endogenous NIR on p53 func- tion, HCT116/p53 $3^{+/+}$cells with an intact p53 response pathway were transiently transfected with siRNAs directed against NIR. In the absence of cellular stress, NIR knock-down resulted in a significant increase in endogenous p 21 protein and mRNA expression in p53-proficient but not in p53-deficient HCT116 cells, thus demonstrating that the observed enhancement of $\mathrm{p} 21$ expression is indeed p53 dependent (Fig. 6F). The p53 protein level was unaffected, indicating increased transcriptional activity of $\mathrm{p} 53$ in response to down-regulation of NIR in the absence of cellular stress. Doxorubicin treatment led to maximal stimulation of p21 expression, which was not further elevated by NIR knock-down (Fig. 6F). Similar results were obtained using a second, independent NIR siRNA (Supplementary Fig. 14). Expression of the proapoptotic p53 target genes BAX, PIG3, and NOXA is not affected by depletion of NIR (Supplementary Fig. 15).

Since NIR is a transcriptional INHAT repressor, we analyzed the acetylation status in the vicinity of p53binding sites following siRNA-mediated depletion of NIR in HCT116/p53 $3^{+/+}$and HCT116/p53-/- cells. In agreement with NIR functioning as an INHAT, ChIP experiments revealed a significant increase in $\mathrm{H} 3 / \mathrm{H} 4$ 
Hublitz et al.

A
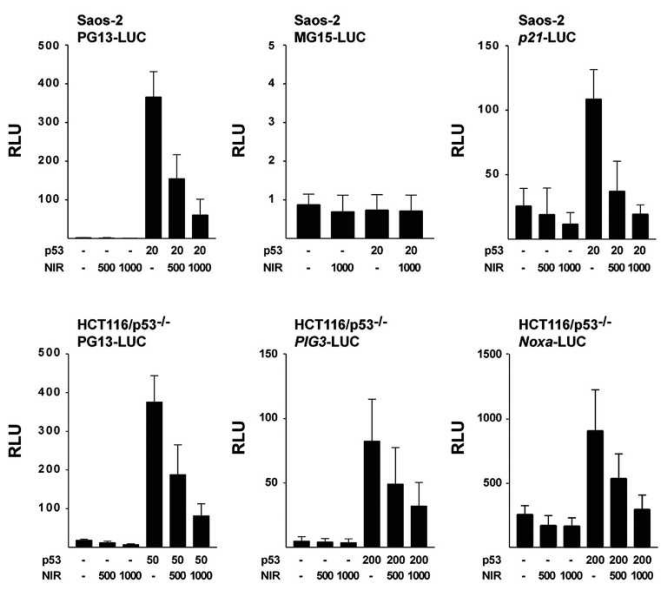

B

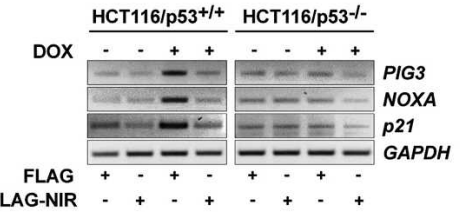

C

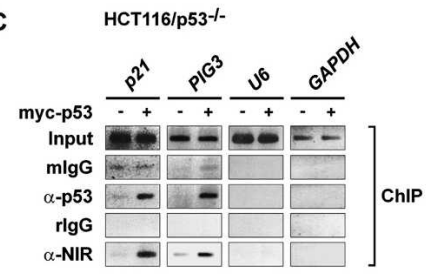

D

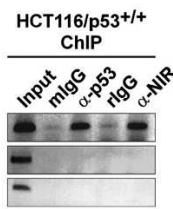

E
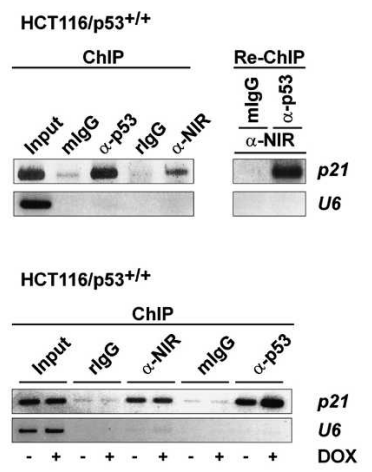

$\mathbf{F}$

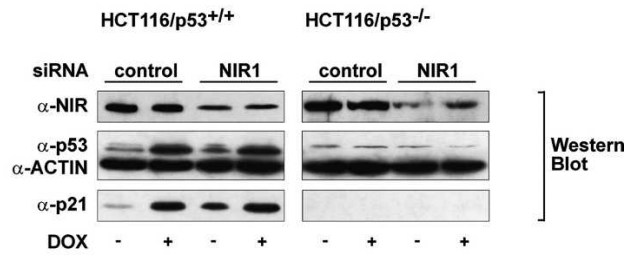

HCT116/p53+/+ HCT116/p53-l-

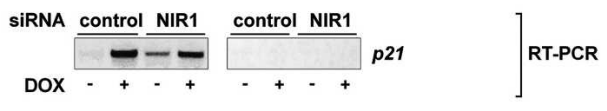

G

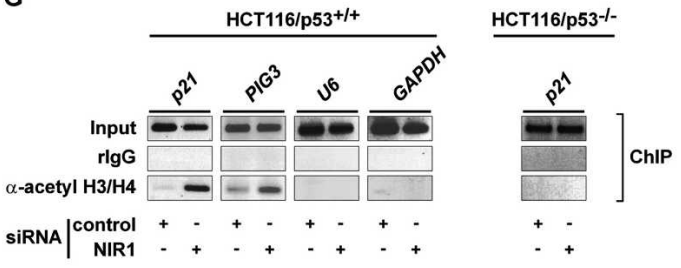

Figure 6. NIR regulates p53 function. (A) NIR represses p53 transcriptional activity. Transient transfections were carried out in the p53-negative cell lines Saos-2 and HCT116/p53-/-. NIR blocks p53-induced expression of the synthetic p53-responsive reporter PG13, whereas the control reporter with mutated p53-binding sites (MG15) is not influenced by either p53 or NIR. NIR represses activation of the known p53 target genes p21, PIG3, and Noxa. (RLU) Relative light units. Bars represent mean \pm SD $(n \geq 6)$. (B) NIR mediates repression of endogenous p53 target genes. Mock-treated or doxorubicin (DOX)-stressed HCT116/p53 $3^{+/}$and HCT116/p53 ${ }^{-/-}$cells were transfected with either a Flag-control plasmid or with a plasmid coding for Flag-NIR. RT-PCR analyses were performed with primers amplifying the p53 target genes PIG3, NOXA, and p21. Amplification of the housekeeping gene GAPDH serves as a control. (C) NIR and 553 are present at endogenous p53-regulated promoters. ChIP assays show that NIR is localized at p53 target promoters in HCT116/p53 ${ }^{-/-}$cells only in the presence of transfected p53. The p53 target genes $p 21$ and PIG3 are precipitated using $\alpha$-NIR (2910) or $\alpha$-p53 (DO-7) antibody. Unrelated promoters (U6 and GAPDH) are not enriched. $(D)$ Endogenously expressed NIR and p53 are present at p53-regulated promoters in HCT116p53 ${ }^{+/+}$cells. In ChIP assays the $p 21$ promoter is precipitated using antibodies directed against either NIR (2910) or p53 (DO-7). The unrelated U6 and GAPDH promoters are not enriched. (E, upper panel) Re-ChIP confirms that NIR and p53 form a complex on the endogenous p21 promoter. First ChIP was performed using the $\alpha$-NIR 2910 antibody. Re-ChIP was performed using either mIgG or the $\alpha$-p53 DO-1 antibody. The unrelated U6 promoter is not precipitated by the antibodies. (Lower panel) NIR and p53 are present at the endogenous $p 21$ promoter in HCT116p53 $3^{++}$cells in the absence $(-)$or presence $(+)$of doxorubicininduced cellular stress. $(F)$ siRNA-mediated NIR knock-down correlates with increased p21 protein and RNA levels in unstressed HCT116/p53 $3^{+/}$cells. Western blotting and RT-PCR analyses were performed at day 3 post-transfection with siRNA. ACTIN serves as a control for equal protein loading. $(G)$ NIR acts as a p53-recruited INHAT in vivo. Knock-down of NIR by siRNA (NIR1) in HCT116/p53 $3^{+/}$cells leads to histone hyperacetylation at p53 target promoters as shown by ChIP assays using a combination of $\alpha$-acetylated $\mathrm{H} 3$ and $\mathrm{H} 4$ antibodies. Unrelated promoters (U6 and GAPDH) are not enriched. The control ChIP from HCT116/p53 ${ }^{-/}$ cells did not reveal changes in the acetylation status of the $p 21$ promoter, thus demonstrating specificity. 
acetylation at target promoters in $\mathrm{HCT} 116 / \mathrm{p} 53^{+/+}$cells upon NIR knock-down (Fig. 6G). No increase in the acetylation status was observed in HCT116/p53-/- cells. Similar results were obtained using the second, independent NIR siRNA (Supplementary Fig. 16). In summary, our data present NIR as a bona fide corepressor of p53 that, upon recruitment, blocks histone acetylation at p53-regulated target promoters in vivo.

\section{Knock-down of NIR leads to increased apoptosis}

Finally, we asked whether NIR controls p53-dependent apoptosis. In HCT116/p53+/+ cells, NIR knock-down robustly increased apoptosis, while treatment of cells with an unrelated control siRNA resulted only in a minimal increase in apoptotic cells (Fig. 7A). Apoptosis induced by NIR depletion peaked at day 3 post-transfection. In

A

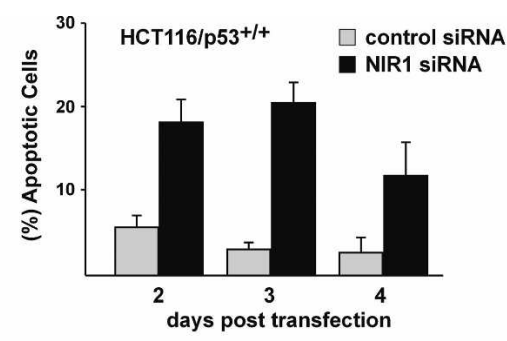

B
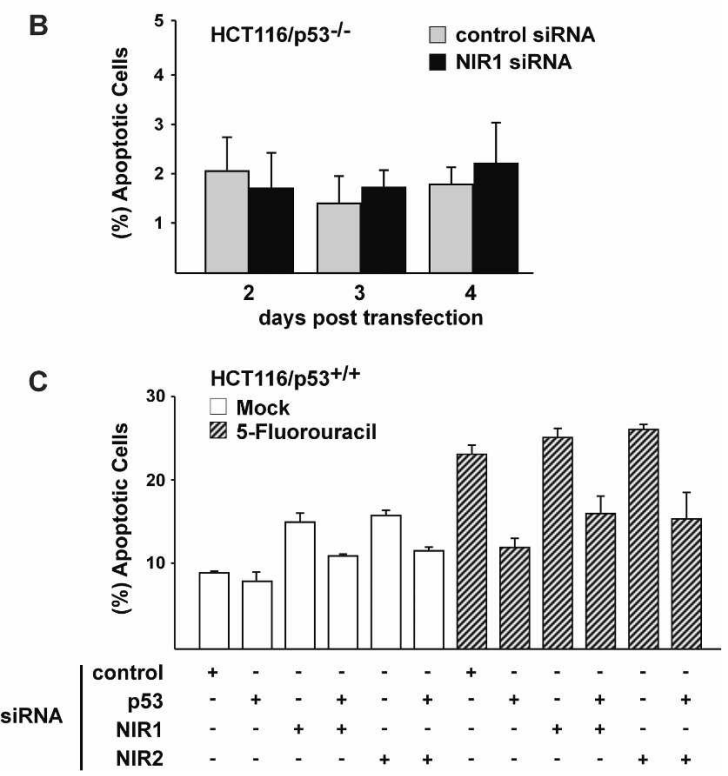

Figure 7. Knock-down of NIR increases p53-dependent apoptosis. NIR knock-down in HCT116/p53 $3^{+/+}$cells results in a strong apoptotic response. p53-containing $(A)$ and p53-deficient $(B)$ HCT116 cells were transfected with either a control siRNA or a siRNA directed against NIR (NIR1). The percentage of apoptotic cells was determined at the indicated time points after transfection. (C) Apoptosis induced by NIR knock-down is p53dependent. HCT116/p53 $3^{+/+}$cells were transfected with either an unrelated siRNA (control) or the indicated combinations of siRNAs directed against p53 or NIR (NIR1 and NIR2). Apoptosis was assessed under unstressed or stress-induced (5-fluorouracil) conditions. Bars represent mean $\pm \mathrm{SD}(n \geq 6)$. contrast, cell survival of HCT116/p53-/- cells was not influenced by knock-down of NIR (Fig. 7B), thus demonstrating that apoptosis induced by NIR depletion is p53 dependent.

In addition, we used a well-characterized siRNA directed against p53 (QIAGEN commercial siRNA \#1027020) to knock down p53 in HCT116/p53 ${ }^{+/+}$cells. Figure $7 \mathrm{C}$ shows that depletion of NIR by the two independent NIR siRNAs (NIR1 and NIR2) specifically increased apoptosis in comparison to the unrelated control siRNA in unstressed HCT116/p53 ${ }^{+/+}$cells. Apoptosis caused by NIR depletion was significantly reduced by simultaneous p53 knock-down. These data strongly suggest that apoptosis induced by NIR depletion is p53 dependent. Finally, we show that p53-dependent apoptosis induced by 5 -fluorouracil was not further increased upon depletion of NIR, indicating that a maximum response of cell death had been reached. Apoptosis induced by treatment of cells with 5-fluorouracil alone or in combination with NIR siRNA was severely impaired by p53 knockdown. In summary, these data show that NIR is critically involved in the regulation of p53-dependent apoptosis.

\section{Discussion}

Iterative BLAST analyses and degenerate, low-complexity screening with the core INHAT domain of the Set/ TAF1 $\beta$ oncoprotein (Seo et al. 2001) allowed us to isolate NIR, a novel INHAT repressor. Enzymatic assays demonstrate that NIR contains two functional INHAT domains. Gal-NIR is a potent repressor independent of the cell line and promoter context analyzed. In contrast to most other known repressors, NIR-mediated repression is not influenced by HDAC inhibitors. Neither TSA or Na-butyrate nor the class III HDAC inhibitor nicotinamide block NIR-mediated repression, pointing to a mechanism that differs from the behavior of previously described repressors. Concomitantly, NIR does not associate with HDACs or diverse members of different corepressor families. These data provide evidence that NIR is a novel HDAC-independent repressor.

In in vitro-assays, full-length NIR and recombinantly expressed NIR INHAT domains directly associate with nucleosomes, core histones, and histone tails. As for Set/ TAF1 $\beta$, association of NIR with the histone tail is sensitive to acetylation, supporting its role as an INHAT to maintain histones in the nonacetylated state. Consequently, acetylation of all core histones by p300 is blocked in the presence of NIR. ChIP analyses further corroborate the in vivo function of NIR as an INHAT, since reduction of endogenous NIR significantly increases histone acetylation at p53 target promoters. In contrast to the Set/TAF1 $\beta$ and pp32 INHATs (Kutney et al. 2004) and the recently described PELP1 (Choi et al. 2004), repression mediated by NIR does not rely on HDAC activity. Accordingly, immunopurified NIR and associated complexes do not contain detectable HDAC activity. Additionally, NIR does not display interaction with known transcriptional corepressors such as N-CoR, 
Smrt, Sin3, SuN-CoR, or HDACs 1, 4, 5, and 6 (Supplementary Fig. 7), and none of the TAP purifications revealed association with known corepressors or INHAT proteins. Furthermore, the ChIP and Re-ChIP experiments clearly demonstrate that although HDACs (such as HDAC1) occupy the endogenous $\mathrm{p} 21$ promoter, NIR and HDAC1 are not present in the same protein complex in vivo (Supplementary Fig. 8). These data indicate that NIR is functionally divergent from PELP1, Set/TAF1 $\beta$, and pp32.

Using a tandem affinity purification approach, we isolated p53 as a NIR-interacting partner. The C-terminal NIR-interaction domain in p53 is distinct from the Sin3interaction site (Zilfou et al. 2001) and coincides with a described repression domain in the $\mathrm{C}$ terminus of p53 (Hong et al. 2001). Recent publications have shown that repression of the p53-regulated stathmin and Map4 promoters requires the recruitment of HDACs by the p53binding partner Sin3 (Murphy et al. 1999), and recruitment of the corepressor CtBP2 is acquired only in presence of the E3 ubiquitin ligase Mdm2 (Mirnezami et al. 2003). In contrast, we demonstrate NIR to be the first INHAT that is able to directly interact with p53 and to modulate p53-mediated transcriptional activation. Whether NIR is also involved in p53-mediated repression is an intriguing question that needs to be addressed in future studies.

The tumor suppressor p53 is thought to function primarily as a transcription factor, which in response to cellular stress binds to target gene promoters (Harris and Levine 2005). However, recent work has documented that p53 can occupy a subset of its target promoters even in the absence of genotoxic stress (Espinosa and Emerson 2001; Kaeser and Iggo 2002). This observation indicates that other mechanisms besides the control of DNA binding are involved in the regulation of p53 transcriptional activity in vivo, setting the requirement for negative regulatory factors. The inhibition of histone acetylation upon association of NIR with promoter-occupying p53 might be such a mechanism. Thus, it is tempting to speculate that $\mathrm{p} 53$ present at promoters in the absence of genotoxic stress functions as a signaling platform for negative regulators to silence transcription. In agreement with this hypothesis, NIR knock-down in unstressed cells results in stimulation of p21 RNA and protein expression. In contrast, the p53-regulated genes PIG3, NOXA, and BAX are significantly stimulated only in response to doxorubicin treatment but not by NIR knock-down. This difference might mirror the recent findings that $p 21$ constitutes a gene of high promoter occupancy by p53 while PIG3 and BAX belong to a group of genes with much lower promoter occupancy (Kaeser and Iggo 2002). Overproduction of NIR robustly inhibited stimulation of the p53 target genes p21, NOXA, and PIG3 upon genotoxic stress in p53-proficient cells, whereas basal expression of these genes in the absence of stress was unaffected. This shows that in stressed cells, p53 activation is, at least in part, counteracted by NIR.

NIR knock-down provokes apoptosis only in p53-containing HCT116 cells. In contrast, HCT116/p53-/- cells do not display any significant cell death upon addition of NIR siRNA, thus demonstrating the physiological importance of NIR in the regulation of p53-mediated apoptosis. However, NIR depletion does not stimulate expression of the proapoptotic genes PIG3, NOXA, and $B A X$, indicating that these genes do not mediate induction of apoptosis in response to NIR knock-down. It is well established that 53 provokes apoptosis not only through the transcriptional activation of proapoptotic genes. In fact, p53-mediated apoptosis is also correlated with the ability of p53 to actively repress genes (Ryan and Vousden 1998). Recent work has indicated that transcriptional repression by p53 may depend on the efficient acetylation of histone tails by HATs (Imbriano et al. 2005). Since NIR is an INHAT, NIR knock-down resulting in elevated histone acetylation thus may support apoptosis by facilitating p53-dependent gene repression.

In summary, our results establish NIR as a novel transcriptional INHAT that directly interacts with p53, inhibits p53-activated gene expression, and regulates p53dependent apoptosis. Future research including the analyses of Nir-deficient mice will shed further light on the impact of NIR on p53 function in cell cycle control, development, and tumorigenesis.

\section{Materials and methods}

\section{Plasmids}

NIR cDNA was obtained by PCR from a prostate cDNA library and cloned into pcDNA6/His-C, pCMX, pCMX-Flag, and pCMX-Gal. Myc-tagged NIR deletion mutants were generated either by PCR or restriction enzyme digestion. Expression plasmids pGEX4T1-NIR-INHAT1 (amino acids 3-147), pGEX4T1NIR-INHAT2 (amino acids 609-749), pRSET-NIR-INHAT1, and $\mathrm{pRSET}-\mathrm{N}^{*} / \mathrm{H}$-NIR-INHAT2 were generated by subcloning the NIR cDNA fragments into the corresponding parental vectors. For TAP analyses, the cDNAs of NIR or NIR deletion mutants were inserted into a modified pCMX expression plasmid (pURB) containing a C-terminal TAP-tag, a flexible polyalanine linker, and, for the NIR deletion mutant, a SV40 nuclear localization signal. Constructs are referred to as pURB-NLSTAP-tag (TAP), pURB-Flag-NIR-linker ${ }_{4 \mathrm{x}}$-TAP-tag (NIR-TAP), pURB-NIR-aa147-609-NLS-TAP-tag (NIR INHAT $\Delta 1 / 2-T A P)$, pURB-NIR-aa609-749-TAP-tag (NIR INHAT2-TAP), and pURBNIR-aa2-147-NLS-TAP-tag (NIR INHAT1-TAP). Lienhart Schmitz (Department of Chemistry, University of Bern, Bern, Switzerland) kindly provided pGEX-human p53. All GST-p53 deletion mutants were generated by PCR and cloned into pGEX4T1. Cloning details are available upon request. All constructs were verified by sequencing. G5E1b-LUC, Gal-TK-LUC, pCMX, pCMX-Gal, and pRSET-N*/H are described (Müller et al. 2002). Other plasmids were kindly provided as follows: p21LUC (Michael Datto, Department of Pathology, Duke University Medical Center, Durham, NC); PIG3-LUC (Matthias Dobbelstein, Institute of Virology, University of Marburg, Marburg, Germany); pGEX-4T1-p300-HAT (Richard Eckner, Institute for Molecular Biology, University of Zurich, Zurich, Switzerland); pCMX-Gal-Nix1, pRSET-Nix1, and pGEX-Nix1 (Erich Greiner, Deutschen Krebsforschungszentrum [KDFZ], Heidelberg, Germany); pGal-TIF2.12 (Hinrich Gronemeyer, Department of Cell Biology and Signal Transduction, Institut de Génétique et de Biologie Moléculaire et Cellulaire [IGBMC], Strasbourg, 
France); pcDNA3.1-myc-p53 (Makoto Hijikata, Institute for Virus Research, Kyoto University, Kyoto, Japan); L8G5-LUC and LexA-VP16 (Saadi Khochbin, Laboratoire Biologie Moléculaire et Cellulaire de la Differenciation, INSERM U309, Institut Albert Bonniot, La Tronche, France); pcDNA3.1-Gal-CREB-Z1A (Marc Montminy, Peptide Biology Laboratories, Salk Institute for Biological Studies, La Jolla, CA); mNoxa-LUC (Xinshou Ouyang, School of Medicine, University of Tokyo, Tokyo, Japan); and the p53 reporters PG13-LUC and MG15-LUC (Bert Vogelstein, Howard Hughes Medical Institute, Johns Hopkins Medical Institutions, Baltimore, MD).

\section{Generation of NIR-specific antibodies}

Proteins corresponding to NIR amino acids 3-147 and amino acids 609-749 were expressed as His-tagged fusion proteins in $E$. coli. Purified proteins were used for rabbit immunization using standard procedures. Antibodies directed against the $\mathrm{N}$ and $\mathrm{C}$ termini ("2719" and "2910," respectively) were affinity-purified.

\section{Cell culture and transient transfections}

For transient transfections, 293, C2C12, BHK, HCT116/p53+/+, HCT116/p53 ${ }^{-/-}$, and Saos-2 cells were cultured in DMEM supplemented with $10 \%$ fetal calf serum, penicillin, streptomycin, and $2 \mathrm{mM}$ glutamine. Transient transfection assays were carried out in 12 -well plates $\left(1 \times 10^{5}\right.$ cells per well $)$ using the calcium phosphate coprecipitation technique. 293 and C2C12 cells were transfected using high molecular weight polyethylenimine (PEI) (Durocher et al. 2002). As indicated, media were replaced with DMEM and 330nM TSA, $5 \mathrm{mM} \mathrm{Na-butyrate,} \mathrm{or}$ $10 \mathrm{mM}$ nicotinamide (all Sigma). The total amount of transfected DNA was kept constant by addition of empty pCMX expression vector and pUC19. Luciferase activity was determined as described (Müller et al. 2002). For mRNA analyses,

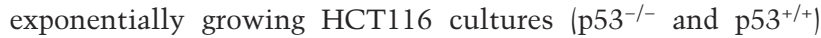
were transiently transfected by Nanofectin (PAA). Twenty-four hours after transfection, subsets of the cultures were treated with $0.34 \mu \mathrm{M}$ doxorubicin (Sigma) for another $6 \mathrm{~h}$.

\section{Immunofluorescence analyses}

Tissue culture cells were treated essentially as described (Müller et al. 2002). Prior to staining, BHK cells were cultured for $6 \mathrm{~h}$ in the presence of $0.34 \mu \mathrm{M}$ doxorubicin (Sigma) to increase p53 protein levels. For primary antibodies, the indicated dilutions were used: $\alpha$-NIR 2910 (1:100), $\alpha$-p53 DO-1 (Calbiochem; 1:250). Localization was visualized using secondary Alexa Fluor 488- and Alexa Fluor 555-labeled antibodies (Invitrogen/Molecular Probes; both 1:7000); nuclei were stained with $1 \mu \mathrm{g} / \mathrm{mL}$ DAPI (Roche). Images were taken with a Zeiss LSM510meta confocal laser scanning microscope.

\section{mRNA analyses}

Total RNA was extracted using the RNAwiz kit (Ambion) followed by isopropanol precipitation. RNA $(6 \mu \mathrm{g})$ was treated with DNase I (Roche) and purified by phenol/chloroform extraction. cDNA synthesis was performed by addition of $100 \mathrm{ng}$ of $\mathrm{dT}_{18^{-}}$ primer using SuperScript reverse transcriptase (GIBCO-BRL). As a control, the housekeeping genes Hprt or GAPDH were amplified for 25 cycles with the following primers: fw, 5'-GTT GAGAGATCATCTCCACC-3'; rv, 5'-AGCGATGATGAACC AGGTTA-3'; and fw, 5'-TGGTATCGTGGAAGGACTCAT GAC-3'; rv, 5'-AGTCCAGTGAGCTTCCCGTTCAGC-3'; re- spectively, at an annealing temperature $\left(\mathrm{T}_{\mathrm{A}}\right)$ of $58^{\circ} \mathrm{C}$. RT-PCR experiments used cDNA amounts according to the control PCR and the indicated primers. PCR oligonucleotides for Nir were $\mathrm{fw}$, 5'-AGAAAGTGCAAGAGAATGCACA-3'; rv, 5'-ACTG GCAGTATGTGCACTGC-3' $\left(\mathrm{T}_{\mathrm{A}}: 60^{\circ} \mathrm{C}, 35\right.$ cycles $)$. For the analysis of p53 target genes, cells were stimulated with $0.34 \mu \mathrm{M}$ doxorubicin for $6 \mathrm{~h}$. The PCR oligonucleotides were p21 (fw, 5'-CCTGGCACCTCACCTGCTCTGCTG-3'; rv, 5'-GCAGAA GATGTAGAGCGGGCCTTT-3'; $\mathrm{T}_{\mathrm{A}}: 60^{\circ} \mathrm{C}, 26$ cycles); PIG3 (fw, 5'-GTGCACTTTGACAAGCCGGGAGGA-3'; rv, 5' -CAG CCTGGGTCAGGGTCAATCCCT-3'; $\mathrm{T}_{\mathrm{A}}: 57^{\circ} \mathrm{C}, 29$ cycles); NOXA (fw, 5'-AGATGCCTGGGAAGAAG-3'; rv, 5'-AGTC CCCTCATGCAAGT- $3^{\prime} ; \mathrm{T}_{\mathrm{A}}: 58^{\circ} \mathrm{C}, 30$ cycles); and Bax (fw, $5^{\prime}-$ CCCCGAGAGGTCTTTTTCCGAGTG-3'; rv, 5'-GAAAAAT GCCCATGTCCCCCAATC- $3^{\prime} ; \mathrm{T}_{\mathrm{A}}: 65^{\circ} \mathrm{C}, 34$ cycles). Northern blot analyses were performed with a human Mutliple Tissue mRNA Dot blot (BD Biosciences Clontech) and a NIR-specific probe spanning base pairs 1447-2250.

\section{Protein expression}

Recombinant proteins were expressed in E. coli using either pRSET (Invitrogen) or pGEX4T1 (GE Healthcare). Expression of proteins was induced by addition of $1 \mathrm{mM} \mathrm{IPTG}$ at $37^{\circ} \mathrm{C}$ for $3 \mathrm{~h}$ for NIR and at $16^{\circ} \mathrm{C}$ for $24 \mathrm{~h}$ for GST-p53 and GST-p53 deletion mutants. Proteins were extracted by sonication in PBS containing $350 \mathrm{mM} \mathrm{NaCl}$ and solubilized by addition of $0.5 \%(\mathrm{v} / \mathrm{v})$ Triton X-100.

\section{Purification of TAP-tagged NIR proteins}

293 cells were transfected with TAP, NIR-TAP, NIR INHAT1TAP, NIR INHAT2-TAP, and NIR $\triangle$ INHAT1/2-TAP as described. Proteins were purified using IgG Sepharose (GE Healthcare). Transfections, cell lysis, and protein purification were performed essentially as described below in the section Tandem Affinity Purification. Equal amounts of the purified NIR proteins were verified by Western blotting using $\alpha$-Protein A $(\alpha$ TAP; Rockland; 1:5000).

\section{GST-pulldown}

Equal amounts of GST or GST fusion proteins were immobilized on GSH Sepharose (GE Healthcare) at $4^{\circ} \mathrm{C}$ for NIR/core histone and NIR/nucleosome interactions or at $37^{\circ} \mathrm{C}$ for NIR/ p53-pulldown assays. Unspecific binding was removed by repeated washing with pulldown buffer $(20 \mathrm{mM}$ HEPES at $\mathrm{pH}$ 7.7; 75-600 mM KCl; 0.1 mM EDTA; $25 \mathrm{mM} \mathrm{MgCl}_{2} ; 10 \mathrm{mM}$ DTT; $0.075 \%-0.5 \%$ NP- 40 ). Thirty micrograms of calf thymus core histones (Roche) or $5 \mu \mathrm{g}$ of nucleosomes prepared from HeLa cells (O'Neill et al. 1992) was mixed with $\left[{ }^{35}\right.$ S $]$ methionine-labeled in vitro translated NIR proteins. Complexes were allowed to form for $1 \mathrm{~h}$ at $4^{\circ} \mathrm{C}$ (NIR/core histone and NIR/nucleosome interactions) or $37^{\circ} \mathrm{C}$ for NIR/p53 interactions. After extensive washing, protein complexes were separated by SDS-PAGE and visualized by Coomassie staining or autoradiography.

\section{Protein A-pulldown}

IgG Sepharose-bound NIR-TAP proteins were washed in pulldown buffer (20 mM HEPES at pH 7.7; $150 \mathrm{mM} \mathrm{KCl} ; 0.1 \mathrm{mM}$ EDTA; $25 \mathrm{mM} \mathrm{MgCl}_{2} ; 10 \mathrm{mM}$ DTT; $0.15 \% \mathrm{NP}-40$ ) and incubated with $5 \mu \mathrm{g}$ of a nucleosomal preparation $\left(\mathrm{O}^{\prime} \mathrm{Neill}\right.$ et al. 1992) for $1 \mathrm{~h}$ at $4^{\circ} \mathrm{C}$. After extensive washing in pulldown buffer, protein complexes were separated by SDS-PAGE and visualized by Coomassie staining. 


\section{Histone tail-pulldown}

Pulldowns with chemically synthesized peptides (corresponding to histone $\mathrm{H} 3$ amino acids 1-30) coupled to Sepharose were performed with $\left[{ }^{35} \mathrm{~S}\right]$ methionine-labeled in vitro translated NIR protein as described (Schneider et al. 2004). Unspecifically bound proteins were removed by washing five times in wash buffer at $4^{\circ} \mathrm{C}(20 \mathrm{mM}$ Tris at $\mathrm{pH} 8.5 ; 150 \mathrm{mM} \mathrm{NaCl} ; 0.5 \%$ NP-40). Protein complexes were separated by SDS-PAGE and visualized by autoradiography.

\section{HDAC assay}

Histone deacetylase activity was measured in immunoprecipitates or whole-cell extracts from 293 cells. Extracts were treated with antibodies directed against the $\mathrm{N}$ or $\mathrm{C}$ terminus of NIR or N-CoR (Santa Cruz; SC-1609). HDAC assays were performed with $\left[{ }^{3} \mathrm{H}\right]$-labeled hyperacetylated histone $\mathrm{H} 3 \mathrm{~N}$-terminal tail peptides as described (Heinzel et al. 1997). As controls, immunopurified N-CoR-containing complexes or $50 \mu \mathrm{g}$ of 293 whole-cell extracts were subjected to HDAC assays with or without $15 \mathrm{~min}$ of preincubation with the HDAC inhibitor TSA (330 nM; Sigma). Mock-treated reactions include histones incubated with IP buffer. The release control displays release of radiolabeled acetyl groups in storage buffer (PBS).

\section{INHAT assays}

Individual core histones $\mathrm{H} 3, \mathrm{H} 2 \mathrm{~B}, \mathrm{H} 2 \mathrm{~A}$, and $\mathrm{H} 4$ were obtained form Roche Molecular Biochemicals. INHAT assays were performed by incubating $2 \mu \mathrm{g}$ of the individual core histone with 1 $\mu \mathrm{g}$ of recombinantly expressed His-INHAT1 or His-INHAT2 in HAT-buffer (Eckner et al. 1996) for $15 \mathrm{~min}$ on ice followed by 15 min at room temperature. As a control, the unrelated cofactor protein Nix1 (Greiner et al. 2000) was incubated with the histones. Following preincubation, active GST-p300 HAT (Eckner et al. 1996) and $25 \mathrm{nCi}$ of $\left[{ }^{14} \mathrm{C}\right]$ acetyl-coenzyme A (GE Healthcare) were added and incubated at $30^{\circ} \mathrm{C}$ for $2 \mathrm{~h}$ under constant shaking at $1000 \mathrm{rpm}$. Reaction products were separated by SDSPAGE, and acetylation was visualized by autoradiography. For INHAT assays with affinity-purified NIR, $3 \mu \mathrm{g}$ of core histones or nucleosomes were used as substrate. INHAT assays were performed as described for the recombinant NIR proteins. After separation by SDS-PAGE, proteins were transferred on PVDF membranes (ImmobilonP; Millipore) and stained with Ponceau $S$ to control for equal loading. Dried membranes were treated with EN $^{3}$ HANCE spray (NEN) and exposed for autoradiography.

\section{Coimmunoprecipitation assays and Western blot analyses}

For coimmunoprecipitations, myc- and TAP-tagged proteins were coexpressed in BHK cells. Whole-cell extracts were prepared in lysis buffer $(50 \mathrm{mM}$ Tris/ $\mathrm{HCl}$ at $\mathrm{pH} 8.0 ; 420 \mathrm{mM} \mathrm{NaCl}$; $0.1 \%$ [v/v] NP-40; $50 \mathrm{mM} \mathrm{NaF} ; 2 \mathrm{mM} \mathrm{Na} \mathrm{VO}_{4} ; 0.2 \mathrm{mM} \mathrm{DTT}$; Complete protease inhibitor cocktail; $20 \%$ [v/v] glycerol). Whole-cell extracts $(300 \mu \mathrm{g})$ were incubated with $3 \mu \mathrm{g}$ of the respective antibodies $(\alpha$-TAP; Rockland; $\alpha$-NIR 2910$)$ in $500 \mu \mathrm{L}$ of lysis buffer. For immunoprecipitation of endogenously expressed proteins, $1 \mathrm{mg}$ of 293 whole-cell extract was incubated with $3 \mu \mathrm{g}$ of specific antibody $\alpha$-p53 (DO-1) or $\alpha$-NIR (2910) in $500 \mu \mathrm{L}$ of RIPA buffer $\left(1 \%\right.$ [v/v] of $1 \mathrm{M} \mathrm{Na}_{2} \mathrm{HPO}_{4}$ solution, buffered to $\mathrm{pH} 7.2$ with $1 \mathrm{M} \mathrm{NaH}_{2} \mathrm{PO}_{4} ; 150 \mathrm{mM} \mathrm{NaCl} ; 1 \%$ NP-40; $0.5 \%$ deoxycholate; $0.1 \%$ SDS; Complete protease inhibitor cocktail). Fifty microliters of pre-equilibrated GammaBind G Sepharose (GE Healthcare) was added for $1 \mathrm{~h}$ while ro- tating at $4^{\circ} \mathrm{C}$. Beads were washed five times with RIPA buffer, and precipitated proteins were analyzed on a $12 \%$ SDS gel. To coimmunoprecipitate endogenous NIR and p53, 293 and

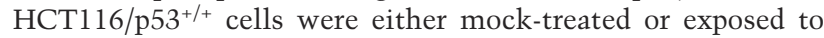
doxorubicin for $6 \mathrm{~h}$. IPs were performed as described (Müller et al. 2002) from $1 \mathrm{mg}$ of nuclear extract in salt-adjusted IP buffer (150 mM) using $5 \mu \mathrm{g}$ of $\alpha$-NIR 2910 or rabbit IgG. Western blots were performed with $15 \mu \mathrm{g}$ of whole-cell extracts. Western blots were decorated with the indicated primary antibodies: $\alpha$-NIR 2910 (1:3000), $\alpha$-p53 DO-1 (Calbiochem; 1:1000), $\alpha$-ACTIN (Sigma; 1:3000), and $\alpha$-p21 (PharMingen; 1:1000). Secondary antibody and chemiluminescence procedures were performed according to the manufacturer (Perkin Elmer).

\section{Immunohistochemical analyses}

Mouse embryos were fixed with $4 \%$ paraformaldehyde and paraffin-embedded. Antibody staining and HRP-coupled detection followed the Vecta Stain Elite kit (Vecta). Epitopes were uncovered by boiling the slides in antibody retrieval solution (Vecta). Primary $\alpha$-NIR antibody $(2719 ; 1: 1000)$ was incubated in $5 \%$ milk powder with $2.5 \%$ horse serum overnight at $4^{\circ} \mathrm{C}$. After repeated washing in PBS/0.1\% Tween 20 , secondary avidin-conjugated antibodies (1:200) were added for $1 \mathrm{~h}$ at room temperature, followed by extensive washing. Biotinylated HRP was added and specific staining was detected using NovaRed HRPsubstrate (Vecta). Nuclei were stained with hematoxylin.

\section{Tandem affinity purification}

TAP purification was essentially performed as described (Rigaut et al. 1999) with the following modifications. 293 cells were transfected using PEI with either TAP, NIR-TAP, or mutants thereof. Approximately $1 \times 10^{8}$ cells were lysed by repeated freeze-thaw cycles in buffer A (20 mM HEPES/KOH at $\mathrm{pH} 7.9$; $420 \mathrm{mM} \mathrm{NaCl} ; 1.5 \mathrm{mM} \mathrm{MgCl}_{2} ; 10 \mathrm{mM} \mathrm{KCl} ; 25 \%$ glycerol; 0.5 mM DTT; $0.1 \%$ NP-40; $0.1 \mathrm{mM}$ EDTA; $50 \mathrm{mM} \mathrm{NaF} ; 0.2 \mathrm{mM}$ $\mathrm{Na}_{3} \mathrm{VO}_{4}$; and Complete protease inhibitor cocktail). TAP-tagged proteins were bound to IgG Sepharose (GE Healthcare) in saltadjusted buffer $\mathrm{A}(150 \mathrm{mM} \mathrm{NaCl})$ at $4^{\circ} \mathrm{C}$ overnight followed by repeated washing. Complexes were released with TEV-protease (100 U; Invitrogen) in TEV buffer (10 mM Tris/ $\mathrm{HCl}$ at $\mathrm{pH} 8.0$; $150 \mathrm{mM} \mathrm{NaCl}$; 0.1\% NP-40; 1 mM DTT; 1 mM EDTA). Complexes containing CBP-tagged NIR were immobilized on a calmodulin affinity resin (Stratagene) for $4 \mathrm{~h}$ at $16^{\circ} \mathrm{C}$. Complexes were washed five times with CBP buffer (10 mM Tris/ $\mathrm{HCl}$ at $\mathrm{pH} 8.0 ; 150 \mathrm{mM} \mathrm{NaCl} ; 0.1 \% \mathrm{NP}-40 ; 1 \mathrm{mM} \mathrm{Mg}$-acetate; $1 \mathrm{mM}$ imidazole; $10 \mathrm{mM} \beta$-mercaptoethanol; $2 \mathrm{mM} \mathrm{CaCl}_{2}$ ) and finally eluted with CBP buffer containing $10 \mathrm{mM}$ EGTA instead of $\mathrm{CaCl}_{2}$. Proteins were size-separated by SDS-PAGE, visualized by Coomassie staining, and identified by MALDI-TOF/TOF.

\section{NIR RNAi and apoptosis assays}

Short interfering RNAs (NIR1, 5'-GACCTGAACTTCCCAGA GATT-3'; NIR2, 5'-GACAGGAAGGATGAAGACATT-3'; p53 siRNA, QIAGEN \#1027020: 5'-GACTCCAGTGGTAATCTA CTT-3') were used to silence gene expression in human HCT116 cells. As a control, an unrelated siRNA targeting luciferase $\left(5^{\prime}\right.$-CGTACGCGGAATACTTCGA-3') was used. Exponentially growing cells were transfected with siRNA (40 nM) by RNAiFect (QIAGEN). With a routine transfection efficiency of $80 \%-90 \%$, a significant knock-down of NIR was observed at days 2-3 post-transfection, but not when cells were transfected with the unrelated control siRNA. At $72 \mathrm{~h}$ post-transfection, cultures were mock-treated or treated with $0.34 \mu \mathrm{M}$ doxorubi- 
cin as indicated. Cells were cultured in normal growth conditions and apoptosis induced by NIR knock-down was determined at the indicated time points by flow cytometry analysis of the numbers of cells with a sub-2n DNA content (MahyarRoemer and Roemer 2001). To assay 5-fluorouracil-induced apoptosis, cultures were mock-treated or exposed to $375 \mu \mathrm{M}$ 5 -fluorouracil $24 \mathrm{~h}$ post-transfection and incubated for another $24 \mathrm{~h}$.

\section{ChIP}

ChIP experiments in HCT116 cells were performed essentially as described (Shang et al. 2002). Immunoprecipitation was performed with $\alpha$-NIR (2910), $\alpha$-p53 (DO-1 or DO-7), and a 1:1 mixture of $\alpha$-acetyl $\mathrm{H} 3 / \alpha$-acetyl H4 (Upstate) antibodies on GammaBind G Sepharose (GE Healthcare). For PCR, 1-5 $\mu \mathrm{L}$ out of $50 \mu \mathrm{L}$ of DNA extractions were used. For Re-ChIP assays, reactions were immunoprecipitated with the $\alpha$-NIR (2910) antibody, and sequentially washed with TSE I, TSE II, buffer III, and TE as described (Shang et al. 2002). Complexes were eluted by incubation in $10 \mathrm{mM} \mathrm{DTT}$ at $37^{\circ} \mathrm{C}$ for $30 \mathrm{~min}$ and diluted 50 times with dilution buffer, followed by a second immunoprecipitation with either the $\alpha$-p53 (DO-1) antibody or mIgG. The primer sequences and PCR conditions used to amplify the corresponding promoter fragments were as follows: p21 (fw, 5'ACСТTTCACCATTCCСCTAC-3'; rv, 5'-GCCCAAGGACAA AATAGCCA-3'; $\mathrm{T}_{\mathbf{A}}: 56^{\circ} \mathrm{C}$ ), PIG3 (fw, 5'-CAGGACTGTCAG GAGGAGGCGAGTGATAAGG-3'; rv, 5'-GTGCGATTCTAG CTCTCACTTCAAGGAGAGG-3'; $\left.\mathrm{T}_{\mathbf{A}}: 63^{\circ} \mathrm{C}\right)$; GAPDH (fw, $5^{\prime}-$ TCCTCCTGTTTCATCCAGC-3'; rv, 5'-TAGTAGCCGGGC CCTACTTT-3'; $\mathrm{T}_{\mathbf{A}}: 60^{\circ} \mathrm{C}$ ); U6 (fw, 5'-GGCCTATTTCCCAT GATTCC-3'; rv, 5' ${ }^{\prime}$-ATTTGCGTGTCATCCTTGC-3' ${ }^{\prime} \mathrm{T}_{\mathbf{A}}: 60^{\circ} \mathrm{C}$ ).

\section{Acknowledgments}

We thank Reinhard Buettner, Thorsten Heinzel, Moshe Oren, Robert Schneider, and Tanja Waldmann for generously providing reagents and support. We are obliged to the members of the Schüle lab, especially Thomas Günther and Holger Greschik, for helpful discussions. We thank Kristin Fischer, Lioba Walz, Sandra Vomstein, Beate Schmitt, Marco Chiabudini, and Benjamin Schüle for excellent technical assistance and the CoreFacility of the University Medical Center for technical support. K.R. was supported by grants from the Wilhelm Sander-Stiftung (2003.007.1) and the Deutsche Forschungsgemeinschaft (RO 1201/10). L.A.v.G. is an FWO fellow. R.S. is supported by grants from the Deutsche Forschungsgemeinschaft (SFB592 and Graduiertenkolleg 1004 Organogenese).

\section{References}

Allison, S.J. and Milner, J. 2004. Remodeling chromatin on a global scale: A novel protective function of p53. Carcinogenesis 25: 1551-1557.

Choi, Y.B., Ko, J.K., and Shin, J. 2004. The transcriptional corepressor, PELP1, recruits HDAC2 and masks histones using two separate domains. J. Biol. Chem. 279: 50930-50941.

Christian, M., Tullet, J.M., and Parker, M.G. 2004. Characterization of four autonomous repression domains in the corepressor receptor interacting protein 140. I. Biol. Chem. 279: 15645-15651.

Deltour, S., Guerardel, C., and Leprince, D. 1999. Recruitment of SMRT/N-CoR-mSin3A-HDAC-repressing complexes is not a general mechanism for $\mathrm{BTB} / \mathrm{POZ}$ transcriptional repressors: The case of HIC-1 and $\gamma$ FBP-B. Proc. Natl. Acad. Sci. 96: 14831-14836.
Durocher, Y., Perret, S., and Kamen, A. 2002. High-level and high-throughput recombinant protein production by transient transfection of suspension-growing human 293-EBNA1 cells. Nucleic Acids Res. 30: E9.

Eckner, R., Yao, T.P., Oldread, E., and Livingston, D.M. 1996. Interaction and functional collaboration of p300/CBP and bHLH proteins in muscle and B-cell differentiation. Genes \& Dev. 10: 2478-2490.

Espinosa, J.M. and Emerson, B.M. 2001. Transcriptional regulation by p53 through intrinsic DNA/chromatin binding and site-directed cofactor recruitment. Mol. Cell 8: 57-69.

Espinosa, J.M., Verdun, R.E., and Emerson, B.M. 2003. p53 functions through stress- and promoter-specific recruitment of transcription initiation components before and after DNA damage. Mol. Cell 12: 1015-1027.

Glass, C.K. and Rosenfeld, M.G. 2000. The coregulator exchange in transcriptional functions of nuclear receptors. Genes \& Dev. 14: 121-141.

Greiner, E.F., Kirfel, J., Greschik, H., Huang, D., Becker, P., Kapfhammer, J.P., and Schüle, R. 2000. Differential liganddependent protein-protein interactions between nuclear receptors and a neuronal-specific cofactor. Proc. Natl. Acad. Sci. 97: 7160-7165.

Harris S.L. and Levine A.J. 2005. The p53 pathway: Positive and negative feedback loops. Oncogene 24: 2899-2908.

Heinzel T., Lavinsky, R.M., Mullen, T.M., Soderstrom, M., Laherty, C.D., Torchia, J., Yang, W.M., Brard, G., Ngo, S.D., Davie, J.R., et al. 1997. A complex containing N-CoR, mSin3 and histone deacetylase mediates transcriptional repression. Nature 387: 43-48.

Hong, T.M., Chen, J.J., Peck, K., Yang, P.C., and Wu, C.W. 2001. p53 amino acids 339-346 represent the minimal p53 repression domain. J. Biol. Chem. 276: 1510-1515.

Imbriano, C., Gurtner, A., Cocchiarella, F., Di Agostino, S., Basile, V., Gostissa, M., Dobbelstein, M., Del Sal, G., Piaggio, G., and Mantovani, R. 2005. Direct p53 transcriptional repression: In vivo analysis of CCAAT-containing G2/M promoters. Mol. Cell. Biol. 25: 3737-3751.

Jepsen, K. and Rosenfeld, M.G. 2002. Biological roles and mechanistic actions of co-repressor complexes. J. Cell Sci. 115: 689-698.

Kaeser, M.D. and Iggo, R.D. 2002. Chromatin immunoprecipitation analysis fails to support the latency model for regulation of p53 DNA binding activity in vivo. Proc. Natl. Acad. Sci. 99: 95-100.

Koipally, J. and Georgopoulos, K. 2002. Ikaros-CtIP interactions do not require $\mathrm{C}$-terminal binding protein and participate in a deacetylase-independent mode of repression. J. Biol. Chem. 277: 23143-23149.

Kutney, S.N., Hong, R., Macfarlan, T., and Chakravarti, D. 2004. A signaling role of histone-binding proteins and INHAT subunits pp32 and Set/TAF-I $\beta$ in integrating chromatin hypoacetylation and transcriptional repression. J. Biol. Chem. 279: 30850-30855.

Lemercier, C., Verdel, A., Galloo, B., Curtet, S., Brocard, M.P., and Khochbin, S. 2000. mHDA1/HDAC5 histone deacetylase interacts with and represses MEF2A transcriptional activity. J. Biol. Chem. 275: 15594-15599.

Li, F., Macfarlan, T., Pittman, R.N., and Chakravarti, D. 2002. Ataxin-3 is a histone binding protein with two independent transcriptional corepressor activities. J. Biol. Chem. 277: 45004-45012.

Liu, G., Xia, T., and Chen, X. 2003. The activation domains, the proline-rich domain, and the $\mathrm{C}$-terminal basic domain in p53 are necessary for acetylation of histones on the proximal p21 promoter and interaction with p300/CREB-binding protein. 
Hublitz et al.

J. Biol. Chem. 278: 17557-17565.

Mahyar-Roemer, M. and Roemer, K. 2001. p21 Waf1/Cip1 can protect human colon carcinoma cells against p53-dependent and p53-independent apoptosis induced by natural chemopreventive and therapeutic agents. Oncogene 20: 3387-3398.

Mirnezami, A.H., Campbell, S.J., Darley, M., Primrose, J.N., Johnson, P.W., and Blaydes, J.P. 2003. Hdm2 recruits a hypoxia-sensitive corepressor to negatively regulate p53-dependent transcription. Curr. Biol. 13: 1234-1239.

Mizzen, C.A., Yang, X.J., Kokubo, T., Brownell, J.E., Bannister, A.J., Owen-Hughes, T., Workman, J., Wang, L., Berger, S.L., Kouzarides, T., et al. 1996. The TAF(II)250 subunit of TFIID has histone acetyltransferase activity. Cell 87: 1261-1270.

Müller, J.M., Metzger, E., Greschik, H., Bosserhoff, A.K., Mercep, L., Buettner, R., and Schüle, R. 2002. The transcriptional coactivator FHL2 transmits Rho signals from the cell membrane into the nucleus. EMBO J. 21: 736-748.

Murphy, M., Ahn, J., Walker, K.K., Hoffman, W.H., Evans, R.M., Levine, A.J., and George, D.L. 1999. Transcriptional repression by wild-type p53 utilizes histone deacetylases, mediated by interaction with mSin3a. Genes \& Dev. 13: 24902501.

Ogryzko, V.V., Schiltz, R.L., Russanova, V., Howard, B.H., and Nakatani, Y. 1996. The transcriptional coactivators p300 and CBP are histone acetyltransferases. Cell 87: 953-959.

O'Neill, T.E., Roberge, M., and Bradbury, E.M. 1992. Nucleosome arrays inhibit both initiation and elongation of transcripts by bacteriophage T7 RNA polymerase. J. Mol. Biol. 223: $67-78$.

Rigaut, G., Shevchenko, A., Rutz, B., Wilm, M., Mann, M., and Seraphin, B. 1999. A generic protein purification method for protein complex characterization and proteome exploration. Nat. Biotechnol. 17: 1030-1032.

Ryan, K.M. and Vousden, K.H. 1998. Characterization of structural p53 mutants which show selective defects in apoptosis but not cell cycle arrest. Mol. Cell. Biol. 18: 3692-3698.

Schneider, R., Bannister, A.J., Weise, C., and Kouzarides, T. 2004. Direct binding of INHAT to H3 tails disrupted by modifications. J. Biol. Chem. 279: 23859-23862.

Seo, S.B., McNamara, P., Heo, S., Turner, A., Lane, W.S., and Chakravarti, D. 2001. Regulation of histone acetylation and transcription by INHAT, a human cellular complex containing the set oncoprotein. Cell 104: 119-130.

Seo, S.B., Macfarlan, T., McNamara, P., Hong, R., Mukai, Y., Heo, S., and Chakravarti, D. 2002. Regulation of histone acetylation and transcription by nuclear protein pp32, a subunit of the INHAT complex. J. Biol. Chem. 277: 14005-14010.

Shang, Y., Myers, M., and Brown, M. 2002. Formation of the androgen receptor transcription complex. Mol. Cell 9: 601610.

Strahl, B.D. and Allis, C.D. 2000. The language of covalent histone modifications. Nature 403: 41-45.

Sun, H. and Taneja, R. 2000. Stra13 expression is associated with growth arrest and represses transcription through histone deacetylase (HDAC)-dependent and HDAC-independent mechanisms. Proc. Natl. Acad. Sci. 97: 4058-4063.

Verdin, E., Dequiedt, F., and Kasler, H.G. 2003. Class II histone deacetylases: Versatile regulators. Trends Genet. 19:286293.

Vogelstein, B., Lane, D., and Levine, A.J. 2000. Surfing the p53 network. Nature 408: 307-310.

Zilfou, J.T., Hoffman, W.H., Sank, M., George, D.L., and Murphy, M. 2001. The corepressor mSin3a interacts with the proline-rich domain of p53 and protects p53 from proteasome-mediated degradation. Mol. Cell. Biol. 21: 3974-3985. 


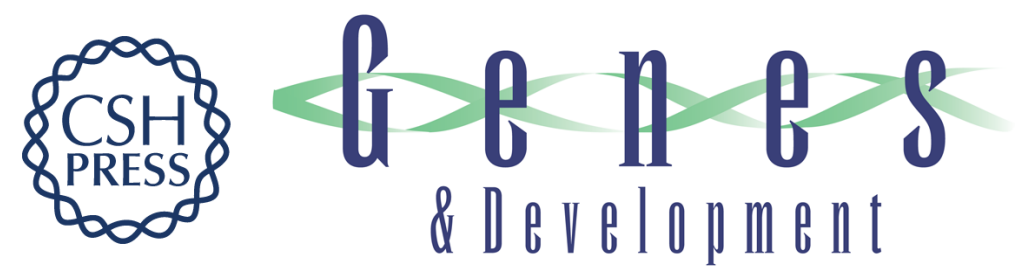

\section{NIR is a novel INHAT repressor that modulates the transcriptional activity of p53}

Philip Hublitz, Natalia Kunowska, Ulrich P. Mayer, et al.

Genes Dev. 2005, 19:

Access the most recent version at doi:10.1101/gad.351205

\section{Supplemental http://genesdev.cshlp.org/content/suppl/2005/11/15/19.23.2912.DC1 Material}

References This article cites 38 articles, 22 of which can be accessed free at: http://genesdev.cshlp.org/content/19/23/2912.full.html\#ref-list-1

\section{License}

Email Alerting

Receive free email alerts when new articles cite this article - sign up in the box at the top Service

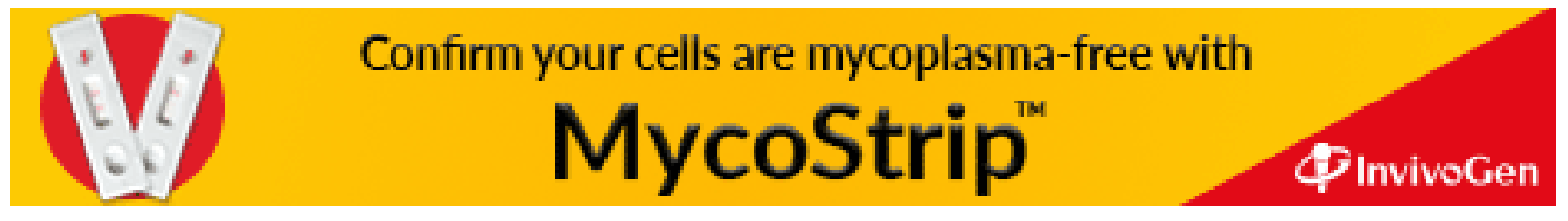

